\title{
ASPECTOS HIGIÊNICO-SANITÁRIOS DE FEIRANTES E ANÁLISE PARASITOLÓGICA DE HORTIFRÚTISCOMERCIALIZADOS EM FEIRAS LIVRES DE MUNICÍPIOS DO ESTADO DE MINAS GERAIS, BRASIL
}

Eunice Pereira SILVA ${ }^{1}$

\author{
Rafaela Aparecida Marques COSTA ${ }^{2}$ \\ Maria Angélica SOARES ${ }^{3}$ \\ Érika Júnia PAULINO ${ }^{4}$ \\ Nadja Maria Gomes MURTA ${ }^{5}$ \\ Harriman Aley MORAIS ${ }^{6}$ \\ João Victor Leite DIAS ${ }^{7}$
}

Herton Helder Rocha PIRES ${ }^{8}$

\begin{abstract}
${ }^{1}$ Nutricionista (UFVJM). Grupo JEQUI/CNPq - Universidade Federal dos Vales do Jequitinhonha e Mucuri. nicesilvadtna@hotmail.com

${ }^{2}$ Grupo JEQUI/CNPq - Universidade Federal dos Vales do Jequitinhonha e Mucuri. rafaelamarquesita@ hotmail.com ${ }^{3}$ Grupo JEQUI/CNPq - Universidade Federal dos Vales do Jequitinhonha e Mucuri. $\underline{m \text { angelicasoares@yahoo.com.br }}$ ${ }^{4}$ Nutricionista. Mestre em Saúde, Sociedade e Ambiente (PPGSaSA). Prefeitura Municipal de Couto de Magalhães de Minas. Grupo JEQUI/CNPq - Universidade Federal dos Vales do Jequitinhonha e Mucuri. erikajupaulino@gmail.com ${ }^{5}$ Programa de Pós-Graduação em Saúde, Sociedade e Ambiente (SaSA). Grupo JEQUI/CNPq - Universidade Federal dos Vales do Jequitinhonha e Mucuri. nadjamurta@gmail.com

${ }^{6}$ Programa de Pós-Graduação em Saúde, Sociedade e Ambiente (SaSA). Grupo JEQUI/CNPq - Universidade Federal dos Vales do Jequitinhonha e Mucuri. hamorais@gmail.com

${ }^{7}$ Enfermeiro. Mestre em Doenças Infecciosas e Parasitárias (CPqRR/FIOCRUZ). Grupo JEQUI/CNPq - Universidade Federal dos Vales do Jequitinhonha e Mucuri. Centro de Pesquisas René Rachou - FIOCRUZ. jvigento@ yahoo.com.br ${ }^{8}$ Biólogo. Doutor em Biologia Parasitária. Programa de Pós-Graduação em Saúde, Sociedade e Ambiente (SaSA). Grupo JEQUI/CNPq - Universidade Federal dos Vales do Jequitinhonha e Mucuri. herton.pires@ufvjm.edu.br
\end{abstract}

\section{Recebido em: 07/09/2015 - Aprovado em: 07/11/2015 - Disponibilizado em: 18/12//2015}

RESUMO:Visto que na maioria das feiras livres as condições higiênicas de comercialização dos produtos alimentícios são insatisfatórias, podendo os feirantes atuar como vetor no processo de contaminação e dispersão de patógenos relacionados às doenças de origem alimentar, o presente estudo teve como objetivo avaliar a estrutura física de feiras livres, os aspectos higiênico-sanitários de feirantesantes e após treinamento sobre boas práticas na manipulação de alimentos, além da contaminação por enteroparasitos em alimentos comercializados nas feirasdequatro municípios da microrregião de Diamantina, Minas Gerais, Brasil. Métodos: Foi preenchido um formulário para avaliação das estruturas físicas das feiras e um questionário acompanhado de checklistpara avaliar as condições higiênico-sanitárias entre73 feirantes antes e após o treinamento. Adicionalmente foram examinadas 58 amostras de hortifrútis comercializados nas feiras para avaliar contaminação por parasitos ou comensais intestinais. Resultados: Asquatro feiras livres apresentavam condições inadequadas quanto à estrutura física dos espaços onde ocorriam. Embora tenha sido observada maior adesão às medidas preventivas na avaliação pós-treinamento, amaioria dos feirantes não estava em conformidade com todas as normas de manipulação de alimentos em ambos os períodos avaliados. A análise de alface, beterraba, cebolinha, cenoura, couve e tomate detectou contaminação por estruturas de helmintos ou protozoários intestinais em $62 \%$ das amostras. Conclusões: Os resultados apontam a necessidade de ações voltadas para melhoria das estruturas das feiras e educação continuada aos feirantes de forma a oferecer alimentos seguros.

Palavras-chave: Feiras livres. Contaminação de alimentos.Manipulação de alimentos.Educação continuada. Análise parasitológica. 


\title{
HYGIENIC-SANITARY ASPECTS OF SELLERS AND PARASITOLOGICAL ANALYSIS OF VEGETABLES SOLD IN OPEN-AIR MARKETS OF MUNICIPALITIES IN MINAS GERAIS STATE, BRAZIL
}

\begin{abstract}
Considering that most of the open-air markets present poor hygienic conditions, and sellers may act as vectors in contamination and spread of food-related illnesses, this study aimed to evaluate the physical infrastructure of open-air markets, the hygienic-sanitary aspects among sellers before and after training on good practices of food manipulation, and the contamination of vegetables sold in open-air markets of four municipalities in micro region of Diamantina, Minas Gerais State, Brazil. Methods: A form was filled out in order to evaluate infrastructure, and a questionnaire accompanied by a checklist was used to evaluate hygiene-sanitary conditions among 73 sellers before and after training. Additionally, 58 samples of vegetables sold at open-air markets were analyzed to evaluate contamination by intestinal parasites or commensals. Results: All open-air markets presented inadequate conditions regarding physical infrastructure at the places where they were organized. Despite more adhesion to preventive attitudes was observed after training, most of the sellers were not in accordance to food manipulation rules at both evaluation periods. Analysis of lettuce, beet, green onion, carrot, kale and tomato revealed contamination by intestinal helminth or protozoa in $62 \%$ of samples. Conclusions: The results indicate the necessity of measures aiming to improve physical infrastructure of openair markets and continuous education of sellers in order to offer customers safe food.
\end{abstract}

Keywords: Open-airmarkets. Foodcontamination.Foodhandling.Continuingeducation.Parasitologicalanalysis.

\section{INTRODUÇÃO}

As feiras livres desempenham importante papel na consolidação econômica e social, sobretudo em pequenos municípios, (GODOY; ANJOS, 2007; SACCO DOS ANOS; GODOY;CALDAS, 2005; PAULINO et al., 2014)por garantir a comercialização da produção familiar, da pequena agroindústria e de produtos artesanais (COUTINHO et al., 2006).As feiras viabilizam o desenvolvimento de relações entre a cidade e o campo (MOREIRA, 2005), e constituemum espaço para a sociabilidade viabilizandoo contato entre as pessoas na comunidade (ALMEIDA; PENA, 2011).

$\mathrm{Na}$ maioria das feiras as condições higiênicas de comercialização dos produtos alimentícios são insatisfatórias, constituindose importante vetor no processo de contaminação e proliferação de doenças de origem alimentar (ALMEIDA FILHO et al., 2003). Os feirantes, trabalhadores da economia informal, em algum momento tornam-se,também, manipuladores de alimentos, podendo ser veiculadores de patógenos para a população (TINOCO et al., 2009).

Para alcançar umcontrole de qualidade dos produtos alimentícios, a detecção e correção das falhas na manipulação, além da adoção de medidas preventivas sãoações indispensáveis, podendo ser desenvolvidas por meio demedidas de educação para adequada manipulação e processamento dos alimentos entre os envolvidosnessas atividades (ALMEIDA et al., 1995).

As hortaliças figuram entre os principais produtos comercializados em feiras livres, sendo frequentemente consumidas in natura. Apesar dos indícios de que hortaliças comercializadas em várias localidades do Brasil apresentam contaminação por fezes humanas ou de animais, poucos trabalhos avaliam o padrão de qualidadedesses alimentos no país (TAKAYANAGUI et al., 
2001; MONTANHER; CORADIN; FONTOURA-DA-SILVA, 2007).

$\mathrm{O}$ presente estudo avaliou as condições de infraestrutura de feiras livres de quatro municípios da região do Vale do Jequitinhonha, Minas Gerais, bem como os aspectos higiênico-sanitários dos feirantes antes e após treinamento sobre boas práticas na manipulação de alimentos.Ademais, investigou-sea ocorrência de estruturas de enteroparasitos em hortifrútis comercializados nestas feiras.

\section{MATERIAL E MÉTODOS}

O estudo, de caráter descritivo e transversal, foi desenvolvido na microrregião de Diamantina, na região do Alto Vale do Jequitinhonha, nordeste do estado de Minas Gerais, abrangendo quatro municípios: Couto de Magalhães de Minas, Datas, Gouveia e São Gonçalo do Rio Preto, que tinham, no censo de 2010, populações de 4.204, 5.210, 11.687 e 3.039 habitantes, respectivamente (IBGE, 2010).

A casuística foi composta por 73 feirantes, sendo 20 de Couto de Magalhães de Minas, 18 de Datas, 16 de Gouveia e 19 de São Gonçalo do Rio Preto, que concordaram emparticipar da pesquisa, assinando o Termo de Consentimento Livre e Esclarecido, erespondendo a um questionário contendo 14 questões (sete fechadas e sete abertas) sobre condições socioeconômicas e das estruturas utilizadas para produção, processamento e transporte de alimentos. As entrevistas foram realizadas nos próprioslocais de trabalho dos feirantes.

As estruturas dos locais de realização das feiras foramavaliadas durante visitasàs feiras, momento em que foi preenchido um formulário pelos pesquisadorescontendonove questões fechadassobre a estrutura física dos espaços de realização das feiras (paredes, telhado e piso, presença de banheiros, pias ebancadas).

Para o diagnóstico dos aspectos higiênico-sanitários dos manipuladores de alimentos, foi preenchido um checklist no primeiro dia de visita às feiras (abril 2013) para cada feirante, com questões sobre as práticas de higiene na manipulação dos alimentos. Para os itens avaliados, eram atribuídas duas possíveis classificações: Conforme, quando as condições observadas eram tidas como satisfatórias segundo legislação RDC $\mathrm{n}^{\mathbf{0}}$ 216, 15 de setembro de 2004 (BRASIL, 2004) e Não conforme, caso fossem consideradas inadequadas.

Diante dolevantamento dos aspectos higiênico-sanitários dos manipuladores de alimento foi elaborado treinamento para os feirantes, o qual foi realizado em maio de 2013, em locais disponibilizados pelas prefeituras, logo após o encerramento das atividades das feiras. Foi utilizada a técnica de exposição dinamizada, que consiste naapresentação oral dos temas de forma dinâmica, utilizando recursos visuais com projeções de imagens, com abertura à 
participação ativa dos feirantes, durante ou após o treinamento.

Foram abordados conceitos fundamentais de boas práticas na manipulação dos alimentos, como: importância das boas práticas, hábitos pessoais e comportamentais na manipulação dos alimentos, contaminação dos alimentos, doenças transmitidas por alimentos, higienização adequada das mãos, diferença entre alimento estragado e contaminado, como preparar solução clorada, higienização dos hortifrútis, do ambiente, de utensílios e equipamentos, armazenamento dos alimentos, cuidados com a água, com o lixo, controle de pragas e rotulagem. Todos os participantes receberam uma cópia de manual de boas práticas e um certificado.

Três meses após o treinamento, os pesquisadores retornaram às feiras para reavaliar os aspectos higiênico-sanitários dos manipuladores por meio de preenchimento do mesmo checklist aplicado anteriormente.

Apresença de estruturas parasitárias foi avaliada nos seguintes hortifrútis: couve, alface, cebolinha, cenoura,beterraba e tomate, escolhidospela aceitação e amplo consumo por parte da população, a ingestão sem nenhumadecocção prévia e sem remoção das cascas, a disponibilidade em todas as épocas do ano e o grandecontato com o solo durante o cultivo.

Os hortifrútis foram comprados em 25 bancas distribuídas entre os quatro municípios, em julho de 2014: alface (13 pés), couve (11 maços ou folhas picadas), cebolinha (quatro maços), tomate (10 pacotes), beterraba (oito pacotes) e cenoura (12 pacotes), totalizando 58 amostras. Não foi quantificado o peso, tamanho ou quantidade que as unidades apresentavam. Os hortifrútis foram mantidos individualizados em sacos plásticos, em geladeira até o momento da realização das análises.A análise parasitológica foi conduzida conforme Oliveira e Germano (1992).

$\mathrm{O}$ projeto aprovado pelo Comitê de Ética em Pesquisa, respeitando a resolução CNS 196/96.

\section{RESULTADOS}

As quatro feiras livres ocorriam semanalmente em espaços cedidos pelas prefeituras em áreas centrais das cidades.

As feiras ocorriam em salões abertos com paredes de alvenaria (inteiras ou meias), exceto em São Gonçalo do Rio Preto, onde havia dois salões, sendo um destinado exclusivamente para lazer (bar com músicas e mesas para jogos de carta). Todos os locais apresentavam iluminação elétrica, piso de cimento, telhado sem laje e com telhas de amianto ou de cerâmica (em Datas). Apenas o município de Gouveia não possuía banheiros e pias. Nos demais, estas instalações eram de uso comum para feirantes e consumidores.

Em Couto de Magalhães de Minas, as bancadas para exposição dos produtos eram de metal (latão). Em Datas, os feirantes utilizavam bancadas de ardósia, contando, 
também, com oito freezers, uma câmara fria e uma balança, de uso coletivo. Em Gouveia, as bancas eram de cimento e não havia pia para higienização das mãos dos feirantes. Em São Gonçalo do Rio Preto, os feirantes expunham seus produtos em bancadas de madeira.

Não havia espaço específico para armazenamento do lixo nas quatro feiras, sendo que em Couto de Magalhães de Minas, Gouveia e São Gonçalo do Rio Preto o lixo era depositado em latões na rua e em Datas os próprios feirantes o levavam para casa.

Quanto ao diagnóstico dos aspectos higiênico-sanitários dos feirantes, detectou-se que todos manipulavam dinheiro juntamente com alimentos e não realizavam higienização das mãos após seu manuseio.

O município de Datas foi o único onde se observou que os todos os feirantes apresentavam vestimenta adequada. Em relação ao uso de adornos (brincos, colares, pulseiras, relógios), o município de Couto de Magalhães de Minas se destacou com 75\% de não conformidades (GRÁFICO1).

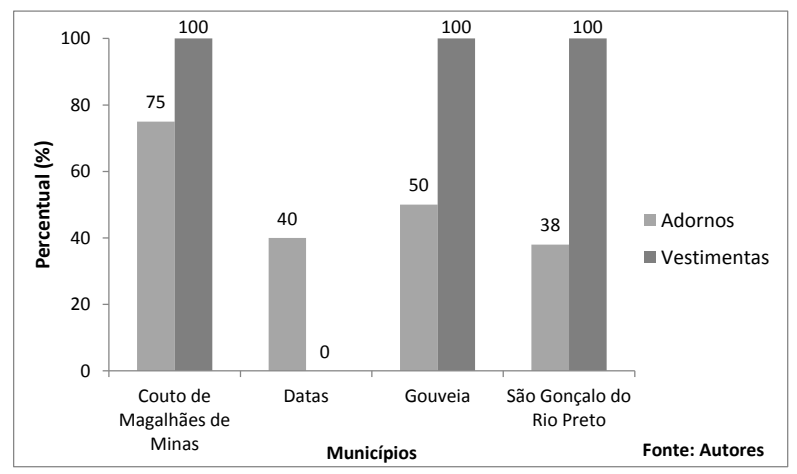

GRÁFICO 1 - Percentual de feirantes em não conformidade com as boas práticas na manipulação de alimentos quanto ao uso de adornos e vestimenta em feiras livres de quatro municípios da microrregião de Diamantina, Minas Gerais, 2013.
Quanto aos aspectos que envolvem a higiene pessoal dos manipuladores: unhas limpas, aparadas e sem esmalte, cabelos protegidos e a inexistência de ferimentos visíveis nas mãos, o município de Datas se destacou com as maiores porcentagens de conformidades (GRÁFICO2).

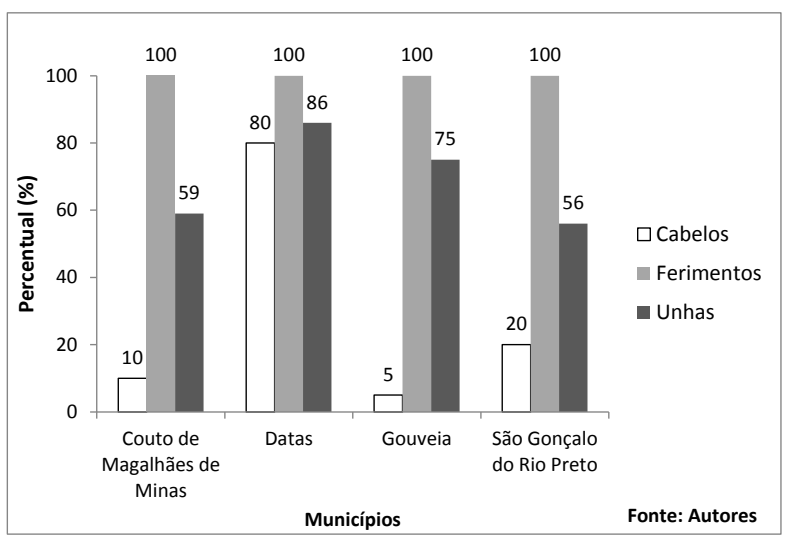

GRÁFICO 2 - Percentual de feirantes em conformidade com as boas práticas na manipulação de alimentos quanto ao uso de adornos e vestimenta em feiras livres de quatro municípios da microrregião de Diamantina, Minas Gerais, 2013.

Quanto às formas de apresentação dos alimentos,emtodas as feiras os hortifrútis eram vendidos in natura, expostos nas bancas ou armazenados em caixas de madeira e/ou plásticas depositadas no chão embaixo das bancas, podendo ou não ser acondicionados em sacos plásticos. Havia oferta de produtos perecíveis, como aves abatidas expostas em sacos plásticos sem nenhum método de conservação.

Os alimentos nas quatro feiras estavam dispostos com separação dos produtos crus dos produtos beneficiados. Em todas as feirasfoi observadacomercialização de alimentos não processados (hortaliças, frutas, aves e ovos),além de produtos de produção 
artesanal (linguiça, queijo, requeijão, doces de leite e de frutas, quitandas, rapadura, mel, fubá, farinha, corante, tempero, cachaça).

Somente duas bancas de doces (uma em Gouveia e outra em São Gonçalo de Rio Preto) apresentavam rotulagem, com informações sobre o nome do produtor e peso do produto. Em São Gonçalo do Rio Preto foi observado que quitandas permaneciam expostas sem qualquer proteção.

Os treinamentos aos feirantes foram viabilizados nas cidades de Couto de Magalhães de Minas, Datas e São Gonçalo do Rio Preto, não sendo possível a realização na cidade de Gouveia por motivos políticos. Em Couto de Magalhães de Minas participaram 20 feirantes, em Datas 18, além de 11 pessoas que os auxiliam nas atividades da feira e em São Gonçalo do Rio Preto 17 feirantes compareceram ao treinamento.

Quanto à adesão às boas práticas após o treinamento, no município de Couto de Magalhães de Minas todos os feirantes continuaram manipulando dinheiro juntamente com alimentos e não realizavam a higienização das mãos após o manuseio do dinheiro e não usavam vestimenta adequada. Em relação ao uso de adornos, de manter unhas limpas, aparadas e sem esmalte e proteção adequada dos cabelos, pode-se observar um aumento nos índices de conformidade(TABELA 1).

No município de Datas, não houve adequação quanto à higiene das mãos. Houve aumento na adequação quanto à manipulação de dinheiro juntamente com alimentos e ao uso de adornos. Em relação ao cuidado de manter as unhas limpas, aparadas e sem esmalte, e proteção adequada dos cabelos houve redução das conformidades (TABELA 1). Quanto à utilização de vestimenta adequada, houve manutenção da total conformidade nas duas avaliações.

No município de São Gonçalo do Rio Preto não houve adequação quanto à higiene adequada das mãos. Houve maior adequação quanto à manipulação de dinheiro juntamente com alimentos, a utilização de adornos, manutenção de unhas limpas e aparadas e proteção dos cabelos (TABELA 1). Apenas um feirante estava em conformidade quanto à vestimenta adequada, fazendo uso do jaleco.

Quanto à inexistência de ferimentos nas duas avaliações todos os feirantes das três feiras foram considerados como conforme.

Entre as 58 amostras de hortifrútis examinadas, $62 \% \quad(n=36)$ estavam positivas para estruturas de enteroparasitos e/ou comensais, tendo sido a Entamoeba coli observada em $32,8 \%$ das amostras, E. nana em 25,86\%, G. lamblia em 1,7\%, larvas de Ancilostomídeos em 8,6\%, ovos de Ancilostomídeos em $3,5 \%$ e larva de Strongyloidesstercoralis em 1,7\%. A hortaliça com maior percentual de amostras contaminadas foi a alface (85\%), seguida pela beterraba $(75 \%)$, couve $(63,6 \%)$, cenoura $(58,3 \%)$, cebolinha $(50 \%)$ e tomate (40\%). A positividade foi observada para hortifrútis de $92 \%$ das bancas (TABELA 2). 
Tabela 1 - Percentual de feirantes em conformidade quanto a aspectos higiênico-sanitários em feiras livres de três municípios de Minas Gerais, antes e após treinamento sobre boas práticas na manipulação de alimentos, 2013.

\begin{tabular}{cccccccccc} 
& \multicolumn{7}{c}{ Aspectos higiênico-sanitários } \\
\cline { 2 - 8 } \multicolumn{2}{c}{ Municípios } & \multicolumn{2}{c}{ Adornos } & \multicolumn{2}{c}{ Cabelo } & $\begin{array}{c}\text { Manipulação } \\
\text { de dinheiro }\end{array}$ & Unhas \\
& Antes & Após & Antes & Após & Antes & Após & Antes & Após \\
\hline Couto de Magalhães de Minas & $25 \%$ & $30 \%$ & $10 \%$ & $15 \%$ & $0 \%$ & $0 \%$ & $59 \%$ & $90 \%$ \\
Datas & $60 \%$ & $75 \%$ & $80 \%$ & $60 \%$ & $0 \%$ & $60 \%$ & $86 \%$ & $60 \%$ \\
São Gonçalo do Rio Preto & $62 \%$ & $78 \%$ & $20 \%$ & $58 \%$ & $0 \%$ & $60 \%$ & $56 \%$ & $82 \%$ \\
\hline
\end{tabular}

Fonte: Autores

Tabela 2 - Análise parasitológica de amostras de seis hortifrútis comercializadas em feiras livre de quatro municípios da microrregião de Diamantina, Minas Gerais, de acordo com o município e a banca de feira, 2014. $(\mathrm{n}=58)$

\begin{tabular}{|c|c|c|c|c|c|c|c|}
\hline Municípios & Bancas & Alface & Cebolinha & Couve & Tomate & Cenoura & Beterraba \\
\hline \multirow{8}{*}{ 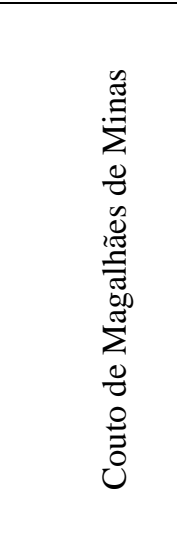 } & 1 & - & - & - & Ena & - & - \\
\hline & 2 & - & - & - & AN & - & - \\
\hline & 3 & - & Ena & - & - & - & - \\
\hline & 4 & Ena & - & Ena & - & - & - \\
\hline & & $E c o$ & & & & & \\
\hline & 5 & AN & - & - & - & Anc-larva & - \\
\hline & 6 & - & $\begin{array}{l}\text { Ena } \\
\text { Eco }\end{array}$ & AN & - & Ena & - \\
\hline & 7 & Eco & - & Eco & - & - & - \\
\hline \multirow{8}{*}{$\begin{array}{l}\stackrel{\tilde{E}}{\tilde{E}} \\
0\end{array}$} & 1 & Eco & - & Ena & - & $\mathrm{AN}$ & - \\
\hline & 2 & Ena & - & - & Eco & - & - \\
\hline & 3 & AN & - & - & - & $\begin{array}{c}\text { Eco } \\
\text { Anc-larva }\end{array}$ & - \\
\hline & 4 & - & - & - & AN & $\begin{array}{c}\text { Eco } \\
\text { Anc-larva }\end{array}$ & Ena \\
\hline & 5 & - & - & Ena & Ena & AN & Anc-ovo \\
\hline & 6 & Eco & - & - & - & - & - \\
\hline & 7 & - & - & AN & - & AN & $S s$ \\
\hline & 8 & - & - & - & - & - & Eco \\
\hline \multirow{6}{*}{$\begin{array}{l}. \frac{\pi}{0} \\
\stackrel{0}{0} \\
0\end{array}$} & 1 & - & - & - & AN & Eco & AN \\
\hline & 2 & - & - & - & Ena & AN & AN \\
\hline & 3 & Eco & - & AN & AN & AN & Eco \\
\hline & 4 & Eco & AN & - & - & - & - \\
\hline & 5 & - & - & AN & AN & - & Eco \\
\hline & 6 & - & AN & Eco & - & $\begin{array}{c}\text { Eco } \\
\text { Anc-larva }\end{array}$ & - \\
\hline
\end{tabular}




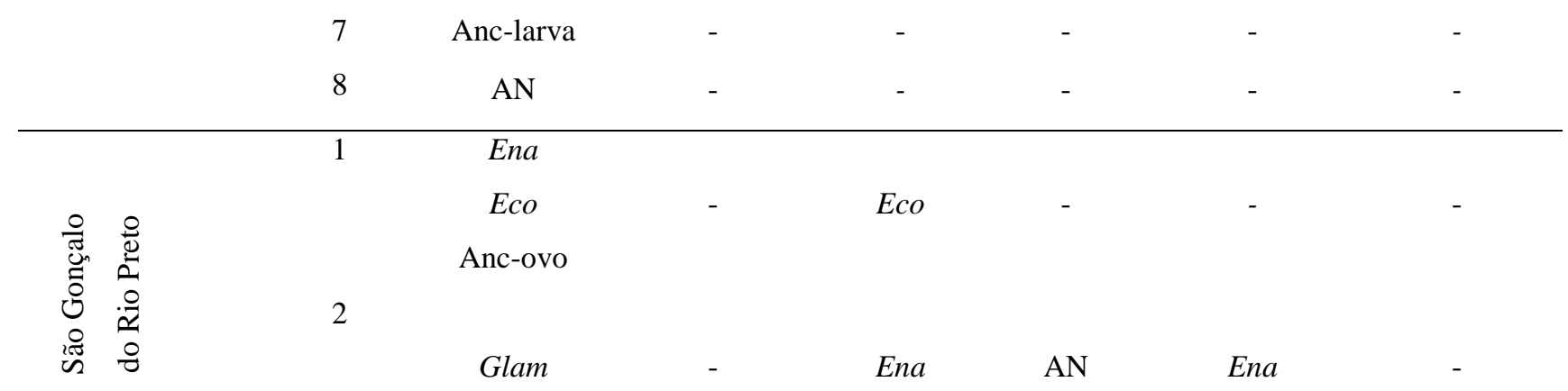

Legenda: (-): Item não disponível na banca; AN: Amostra negativa; Anc-larva: larvas de ancilostomídeos; Anc-ovo: ovos de ancilostomídeo; Ena: cistos de Endolimax nana; Eco: cistos de Entamoeba coli; Glam: cistos de Giardialamblia;Ss: larvas de Strongyloidesstercoralis.

Fonte: Autores.

\section{DISCUSSÃO}

As condições higiênico-sanitárias da estrutura física das feiras dos quatro municípios foram, no geral, insatisfatórias. De acordo com a resolução RDC n $^{\mathbf{0}}$ 216/2004, os locais onde há manipulação de alimentos devem possuir lavatórios e estar supridos de produtos destinados à higiene pessoal tais como sabonete líquido inodoro anti-séptico e toalhas de papel não reciclado.

A falta de uma legislação específica sobre a estrutura física das feiras livres não assegura a presença de estruturas para higienização pessoal e dos alimentos durante a comercialização, o que pode aumentar a exposição e contaminação por microrganismos (ESTEVES; FIGUERÔA, 2009; SOARES; CANTOS, 2005).

As bancas de madeira e cimento apresentam superfícies irregulares, o que dificulta a higienização adequada, propiciando o acúmulo de sujidades e a consequente contaminação por microrganismos (ABREU; CABRAL, 2005). As bancas de metal (latão), por sua vez, são propícias à oxidação, principalmente em ambientes expostos a intempéries, o que pode levar à contaminação dos produtos comercializados. Nesse sentido, a resolução RDC $n^{0}$ 216/2004 reza que os móveis que entram em contato com alimentos devem ser de materiais que não transmitam substâncias tóxicas aos mesmos, além de serem resistentes à corrosão e a repetidas operações de limpeza e desinfecção. Assim sendo, as bancas de ardósia foram as únicas que atendiam a estes critérios, por apresentar superfície uniforme e de fácil higienização (CASTRO et al.,2011).

Ao contrário do que se preconiza na legislação a respeito de conservação de produtos cárneos que devem ser mantidos a temperatura máxima de $4^{\circ}$ C, (CVS, 2013; DVS 2015), nas quatro feiras tais alimentos eram acondicionados unicamenteem sacos plásticos, sem nenhuma condição de conservação. Mesmo no único município que dispunha de equipamentos para refrigeração, 
os feirantes alegaram que raramente utilizavam, pois, segundo eles, não permitiam exposição dos produtos ao consumidor.

Outro ponto crítico observado nas feiras foi a ausência de proteção nas quitandas e doces expostos, o que eventualmente possibilita o contato destes alimentos com agentes carreadores de microrganismos com potencial patogênico, podendo causar a contaminação e consequentemente colocar em risco a saúde do consumidor (THYSSEN et al., 2004). Além disso, a falta de rotulagem nos produtos contraria a Resolução $n^{\circ}$ 259, 20 de setembro de 2002 (BRASIL, 2002), que preconiza o uso do rótulo quando o produto for embalado na ausência do consumidor.

A relevante quantidade de estruturas de parasitos e comensais intestinais nos hortifrútis analisados revela possíveis falhas na produção, transporte, armazenamento ou manipulação dos alimentos. A ausência de procedimentos higiênico-sanitários adequados durante a produção ou comercialização desses alimentos pode favorecer a exposição aos dejetos fecais humanos ou de animais, incluindo helmintos e protozoários intestinais.

No presente estudo, o principal protozoário intestinal encontrado foi a E. coli, o que corrobora outros estudos realizados no Brasil (GUILHERME et al., 1999, NEVES et al., 2011). Apesar de este protozoário, assim como a E. nana, ser comensal do trato digestivo humano, não causando danos ao hospedeiro, sua presença sinaliza a contaminação fecal nas hortaliças. De igual forma, também protozoários intestinais patogênicos que compartilham a mesma via de infecção (fecal-oral), podem estar presentes nesses alimentos, como a presença de G. lamblia observada nesse estudo. Por outro lado, a presença de estruturas infectantes de helmintos que possuem formas de vida livre no solo, como ancilostomídeos e S. stercoralispode indicar contaminação desses hortifrútis nos locais de cultivo, remetendo às condições sanitárias precárias, principalmente no que se refere ao saneamento ambiental (CARVALHO; CARVALHO;MASCARINI, 2006; PINHEIRO et al., 2011).

Assim como nos trabalhos de Falavignaet al.(2005) e Andrade, Silva e Stamford (2005) a alface representou o hortifrúti com maior contaminação, o que é explicado pela estrutura das folhas (largas, múltiplas e justapostas) permitindo uma melhor e maior fixação das estruturas parasitárias. A flexibilidade das folhas pode facilitar o contato com o solo durante o cultivo, favorecendo a contaminação (SILVA; ANDRADE;STAMFORD, 2005). Sendo a principal hortaliça produzida e consumida no Brasil (BANDEIRA et al., 2011), a alface pode se tornar um importante fator na transmissão das enteroparasitoses.

Ribeiro et al. (2005) afirmam que, embora sejam importantes para feirantes, consumidores, para o comércio e a cultura local, raramente as feiras livres recebem atenção de programas governamentais. Isso 
revela a invisibilidade econômica de atividades locais, a marginalização da agricultura familiar nos programas de desenvolvimento dos municípios e, mais ainda, demonstra o caráter produtivista dos programas públicos.

\section{CONCLUSÕES}

Ante o exposto, é possível concluir que há necessidades de adequações nas feiras livres tanto no que se refere à infraestrutura dos locais de realização, quanto às boas práticas na manipulação de alimentos entre os feirantes. Além disso, as mudanças observadas após o treinamento apontam a importância do processo de educação para melhoria da qualidade do serviço. Entretanto,para que sejam alcançados melhores resultados, há necessidade de que as ações sejam sustentadas numa perspectiva longitudinal, com participação ativa do poder público municipal, e envolvimento de instituições de ensino.

\section{REFERÊNCIAS}

ABREU, S.C.; CABRAL, M.M.W. Análises microbiológicas de placas de corte de madeira para identificação de bactérias pertencentes ao grupo das Enterobacteriaceae. Investigação - Revista Científica da Universidade de Franca.v. 5, n. 1-6, 132-138, 2005.

ALMEIDA, R.C.C. et al. Avaliação e controle da qualidade microbiológica de mãos de manipuladores de alimentos. Revista de Saúde Pública. v. 29, n. 4, p. 290-294,1995.
ALMEIDA, M.D.; PENA, P.G.L. Feira livre e risco de contaminação alimentar: estudo de abordagem etnográfica em Santo Amaro, Bahia. Revista Baiana de Saúde Pública. v.35, n.1, p.110-127, 2011.

ALMEIDA-FILHO, E.S. et al. Pesquisa de Salmonella spp. em carcaças de frango (Gallusgallus) comercializadas em feira livre ou supermercado no município de Cuiabá, MT, Brasil. RevistaHigiene Alimentar.v.17, n. 110,p.74-79, 2003.

BANDEIRA, G.R.L.et al. Manejo de irrigação para o cultivo de alface em ambiente protegido. Horticultura Brasileira.v. 29, n. 2, p. 237-241, 2011.

BRASIL. Resolução RDC n 259, 20 de setembro de 2002. Aprova o Regulamento Técnico sobre Rotulagem de Alimentos Embalados. Agência Nacional de Vigilância Sanitária. Diário Oficial da União. Brasília, DF, 23 set. 2002.

BRASIL. Resolução RDC n ${ }^{\circ}$ 216, 15 de setembro de 2004. Dispõe sobre Regulamento Técnico de Boas Práticas para Serviços de Alimentação. Agência Nacional de Vigilância Sanitária. Diário Oficial da União. Brasília, DF, 16 set. 2004.

CARVALHO, T.B.; CARVALHO, L.R.; MASCARINI, L.M. Occurrence of enteroparasites in day care centers in Botucatu (São Paulo State, Brazil) with emphasis on Cryptosporidium sp., Giardia duodenalisand Enterobiusvermicularis. Revista Instituto de Medicina Tropical de São Paulo.v.48, n. 5, p. 269-273, 2006.

CASTRO, J.O. et al. Uso de ardósia na construção de celas de maternidade: I - Efeito sobre o ambiente e comportamento de suínos. Engenharia Agrícola.v.31, n. 3, p. 458-467, 2011.

COUTINHO, E.P. et al. Feiras livres do brejo paraibano: crise e perspectivas. In: XLIV CONGRESSO DA SOCIEDADE BRASILEIRA DE ECONOMIA E 
SOCIOLOGIA RURAL, 2006, Fortaleza, Anais...Fortaleza: SOBER, 2006. Disponível em: www.sober.org.br/palestra/5/663.pdf

ESTEVES, F.A.M.; FIGUERÔA, E. O. Detecção de enteroparasitas em hortaliças comercializadas em feiras livres do município de Caruaru (PE). Revista Baiana de Saúde Pública. v. 33, n. 2, p. 184-193, 2009.

GODOY, W.I.; ANJOS, F.S. A importância das feiras livres ecológicas: um espaço de troca e saberes da economia local. Revista Brasileira de Agroecologia, v. 2, n. 1, p. 364-368, 2007.

FALAVIGNA, L.M. et al. Qualidade de hortaliças comercializadas no noroeste do Paraná, Brasil.

ParasitologíaLatinoamericana.v.60, n. 3-4, p. 144-149, 2005.

GUILHERME, A.L.F. et al. Prevalência de enteroparasitas em horticultores e hortaliças da Feira do Produtor de Maringá, Paraná. Revista da Sociedade Brasileira de Medicina Tropical. v.32, n. 4, p. 405-411, 1999.

IBGE - Instituto Brasileiro de Geografia e Estatística. Censo demográfico 2010. Rio de Janeiro: IBGE; 2010.

MONTANHER, C.C.; CORADIN, D.C.; FONTOURA-DA-SILVA, S.E. Avaliação parasitológica em alfaces (Lactuca sativa) comercializadas em restaurantes self-service por quilo, da cidade de Curitiba, Paraná, Brasil. Estudos de Biologia.v. 29, n. 66, p. 63-71, 2007.

MOREIRA, R. Sociedade e espaço (As formas de organização geográfica das sociedades na era da terceira revolução industrial - um estudo de tendências). Agrária. v. 2, p.93-108, 2005.

NERES, A.C. et al. Enteroparasitos em amostras de alface (Lactuca sativa var. crispa), no município de Anápolis, Goiás, Brasil. BioscienceJournal. v. 27, n. 2, p. 336341, 2011.
OLIVEIRA, C.A.F.; GERMANO, P.M.L. Estudo da ocorrência de enteroparasitas em hortaliças comercializadas na região metropolitana de São Paulo, SP, Brasil: I Pesquisa de helmintos. Revista de Saúde Pública.v. 26, n. 4, p. 283-289, 1992.

PAULINO, E.J. et al. A agricultura familiar em um município do Alto Jequitinhonha, Minas Gerais. Revista Desenvolvimento Social. v. 13, p.5-20, 2014.

PINHEIRO, I.O.et al. Prevalence and risk factors for giardiasis and soil-transmitted helminthiasis in three municipalities of Southeastern Minas Gerais State, Brazil. Parasitology Research. v. 108, n. 5, p. 11231130, 2011.

RIBEIRO, E.M. et al. Programa de Apoio às Feiras e à Agricultura Familiar no Jequitinhonha mineiro.Agriculturas.v. 2, n. 2, p. 5-9, 2005.

SACCO DOS ANJOS, F.; GODOY, W.I.; CALDAS, N.V. As feiras-livres de Pelotas sob o império da globalização: perspectivas e tendências. Pelotas: Editora e Gráfica Universitária, 2005. 197p.

SÃO PAULO (Estado). Portaria CVS 5, 09 de abril de 2013. Aprova o regulamento técnico sobre boas práticas para estabelecimentos comerciais de alimentos e para serviços de alimentação, e o roteiro de inspeção, anexo. Centro de Vigilância Sanitária. Diário Oficial do Estado. São Paulo, SP, 19 abr. 2013.

DISTRITO FEDERAL. Instrução Normativa $\mathrm{n}^{\circ} 04,15$ de dezembro de 2014. Aprova o regulamento técnico sobre boas práticas para estabelecimentos comerciais de alimentos e para serviços de alimentação, e o roteiro de inspeção, anexo. Diretoria de Vigilância Sanitária. Diário Oficial do Distrito Federal. Brasília, DF, 11 fev. 2015.

SILVA, C.G.M.; ANDRADE, S.A.C.; STAMFORD, T.L.M. Ocorrência de Cryptosporidium spp. e outros parasitas em hortaliças consumidas in natura, no Recife. 
Ciência \& Saúde Coletiva. v.10, n. Sup, p. 63-69, 2005.

SOARES, B; CANTOS, G.A. Qualidade parasitológica e condições higiênicosanitárias de hortaliças comercializadas na cidade de Florianópolis, Santa Catarina, Brasil. Revista Brasileira de

Epidemiologia.v.8, n. 4, p. 377-384, 2005.

TAKAYANAGUI, O.M.et al. Fiscalização de verduras comercializadas no município de Ribeirão Preto, SP. Revista da Sociedade Brasileira de Medicina Tropical.v. 34, n.1, p. 37-41, 2001.

THYSSEN, P.J. et al. O papel de insetos (Blattodea, Diptera e Hymenoptera) como possíveis vetores mecânicos de helmintos em ambiente domiciliar e peridomiciliar.

Cadernos de Saúde Pública. v.20, n. 4, p. 1096-1102, 2004.

TINOCO, B.O.W. et al. Avaliação das condições higiênico-sanitárias dos manipuladores de alimentos das barracas da feira livre de Seropédica, RJ. In: XX CONGRESSO BRASILEIRO DE ECONOMIA DOMÉSTICA, 2009, Fortaleza. Anais...2009.Fortaleza:CBED. Disponível em: www.xxcbed.ufc.br/arqs/gt6/gt6_25.pdf 